Please quote as: Weinert, T.; Janson, A. \& Leimeister, J. M. (2020): Does Context Matter for Value Co-Creation in Smart Learning Services? In: Gronau, N., Krasnova, H., Pousttchi, K. \& Heine, M. (Eds.), 15th International Conference on Wirtschaftsinformatik (WI 2020). 


\title{
Does Context Matter for Value Co-Creation in Smart Learning Services?
}

\author{
Tim Weinert $^{1}$, Andreas Janson ${ }^{1}$, Jan Marco Leimeister ${ }^{1,2,}$ \\ ${ }^{1}$ University of Kassel, Information Systems, Kassel, Germany, ${ }^{2}$ University of St. Gallen, \\ Information Systems, St. Gallen, Switzerland \\ \{tim.weinert, andreas.janson, leimeister\} @uni-kassel.de
}

\begin{abstract}
Smart learning services offer customized learning solutions by systematically considering the context of the learner. However, it is still unclear how the value co-creation within smart learnings is affected by context considerations. Therefore, it is important to understand how the context can influence the value co-creation potential in smart learning services. To investigate how context shapes value co-creation smart learning services, we first conduct a systematic literature review to investigate context factors within learning processes. Afterwards, we develop a conceptual model to explain how context in smart learning systems can be used to enhance the co-creation potential in learning processes. Overall, we provide a better understanding of context considerations in service systems as a theoretical contribution of our conceptual investigation. Finally, we provide practical implications for educational service providers for designing smart learning services under the specific consideration of different contexts.
\end{abstract}

Keywords. Context; Smart product; Value Co-Creation; Service system

\section{Introduction}

With the increasing spread of information and communication technologies, smart learning services that rely on smart devices drive profound changes in value co-creation [1]. These smart devices are often used for service provision [2], such as providing trainings in different contexts [3]. Smart devices use input from learners and contextual information to provide assistance by guiding the learner through the learning process $[4,5]$. The aim of this assistance is to enhance the collaboration between learners and the overall learning system to enhance learning outcomes such as more knowledge acquisition. Hence, smart devices can offer entirely new ways of engaging learners. Through innovative interaction possibilities, value can be co-created between organizations and learners, for example, by giving the possibility to design flexible learning processes that can adapt to the individual needs of the learners. This enables the learners to self-organize their learning process efficiently [6], especially in the domain of vocational trainings [3].

However, while more and more companies are relying on smart devices for the provision of their trainings, neither research nor practice have a clear understanding of

$15^{\text {th }}$ International Conference on Wirtschaftsinformatik,

March 08-11, 2020, Potsdam, Germany 
how the nature of these systems shapes value co-creation processes. From a learning theory perspective, learners in vocational training situations often struggle with their learning process because existing learning opportunities do not tailor to the learners' needs [7]. In this light, addressing learning opportunities that are adapted to these needs in a targeted way can help to overcome these problems. The targeted address of learning opportunities is possible through the consideration of context factors in the learning process [5]. However, to describe the co-creation potential in learning systems, we need to understand how context can influence the learning process. Considering contextual factors such as adapting learning content to the skill level of learners provides challenging but not frustrating learning processes, therefore leading to an increased value of the learning system. In consequence, we assume that smart learning systems require a deeper understanding of the application field, based on the context and learning process information that enable the design of individualized and adaptive learning systems.

Our paper addresses these challenges by developing a conceptual framework for value co-creation within smart learning services based on the capabilities of smart, connected products [8]. Thereby, we aim to understand learning initiatives in multiple contexts from a service system theory perspective, which helps us to explain what value smart products in context-adaptive learning systems can have. In our study, we first identify context factors in learning processes by conducting a systematic literature review following the assumptions given by Webster and Watson [9] and Vom Brocke et al. [10]. As Zheng and Yano [11] mentioned, the number of possible context factors can be high. Therefore, we want to reduce the set of context factors to the most important ones for the vocational learning process. In the second step, we want to develop a conceptual model that helps us to explain how the context in smart learning systems can be used to enhance the co-creation potential of the process. Thereby, we explain how smart products can improve this interaction and enable the inclusion of several context factors that cannot be captured by conventional systems [12]. Following our goal, we aim to answer the following research question (RQ):

RQ:

How do context factors influence the value co-creation process in smart learning?

Our results contribute to theory by providing a structure to classify contextual factors within learning processes. Moreover, we can show which context factors are important for smart learning services. Building on this, we design a conceptual model to explain how the recognition of context helps to create value within smart learning systems and how the consideration of context factors can enhance the peer-creation potential in smart learning service systems.

\section{Value Co-Creation in Smart Learning Services and Context}

Smart learning services can be considered as a subset of technology-mediated learning (TML) that tries to integrate synchronous (i.e., face-to-face) and asynchronous (i.e., technology-based) learning approaches $[6,13]$. In contrast to typical TML approaches, however, smart learning services are conceptualized through the integral component of 
smart products. These smart products offer the possibility to connect the digital world with the physical world and therefore enable capturing individual context data about the user of the product. By using sensors, smart products, such as smartphones or smart personal assistants like Amazon's Echo devices, can obtain contextual data, can communicate with other products and actors and thus enable completely new possibilities in the design of services $[8,14]$. As such, these smart learning systems can enable learners to learn in the real world with support from the digital world [15].

These approaches should help learners to organize their learning process independently. In particular, the interaction between several learners and a teacher is an important prerequisite for a successful learning process [16]. This interaction involves the exchange of learning content and knowledge about possible learning paths that fit the learners' personal learning process. Thereby, it enables new knowledge for each of the actors, such as new process knowledge for the learner or new pedagogical skills for the peers. The consideration does not differ too much from what we understand as "traditional" service [17]. These services are human-centered processes in which value is co-created by the interaction of two or more actors (i.e., individuals or organizations) [18]. At the same time, the notion of smart service considers the value co-creation between humans and smart products [18], also strongly depending on the context of a learner. On the one hand side, the in-use value for the learner is created by having a better support within the learning process (i.e., the right learning material in the right time). On the other side, the consideration of context factors can enhance the in-used value for the organizations due to a deeper understanding of their work processes as well as fast and high-quality trainings.

Directly intertwined is context, which in general can be defined as "any information that can be used to characterize the situation of an entity. An entity is a person or object that is considered relevant to the interaction between a user and an application, including the user and the application themselves" [19]. Oftentimes, possible context factors in learning processes are difficult to determine because the amount of factors can be very large $[11,20]$. Thus, various authors develop frameworks to grasp the context within the environmental situation and to reduce the number of context factors [11, 21, 22]. However, as Hong et al. [23] mentioned, the context is often not sufficiently taken into account in the development of artifacts and models. Therefore, possible context factors should be considered by the design of smart learning services.

Viewing the learning process as a service process can help to understand how the consideration of context factors can enhance the learning in TML. By using smart products, a broad spectrum of information can be collected within the learning process by the sensors of the product as well as through user input. The information about the condition of the context factors can serve as a basis for high-quality learning services [24]. By using smart products, the sensors can capture the context factors that occur at the time of measurement. Moreover, these smart products can make decisions independently and thus reduce the effort of the learning process [20]. Therefore, we define smart learning services as the usage of smart products to consider context factors within learning services. 


\section{$3 \quad$ Methodology}

The research design and method of this study are based on an understanding that context factors in learning systems can help to improve the learning process in TML. The connection to service systems can help to understand the effect of these factors on the value co-creation in smart learning systems $[17,25]$. That is why it is important to conceptualize a smart learning system that can respond to the context of the learner to understand how this connection affects the learning process. In order to review the current literature, our methodology follows the literature review process of Webster and Watson [9], which comprises the steps of finding, coding, selection, and an analyzing process in a structured way. To clarify our research scope, we used the taxonomy suggested by Cooper [26]. The research scope can be seen in table 1 .

Table 1: Definition of the Research Scope

\begin{tabular}{|c|c|c|c|c|}
\hline Focus & Research Methods & Research Outcome & Theories & $\begin{array}{c}\text { Practices or } \\
\text { Applications }\end{array}$ \\
\hline Goal & Integration & Criticism & Identification of Central Issues \\
\hline Organization & Historical & Conceptual & \multicolumn{2}{|c|}{ Methodological } \\
\hline Perspective & \multicolumn{2}{|c|}{ Neutral Representation } & \multicolumn{2}{|c|}{ Espousal of Position } \\
\hline Audience & Specialized Scholars & General & Practitioners & Public \\
\hline Coverage & Exhaustive & $\begin{array}{c}\text { Exhaustive with } \\
\text { selective Citation }\end{array}$ & Representative & Central \\
\hline
\end{tabular}

In our review, we focus on the outcome of the articles in order to identify the central issues. Due to the conceptual character of our research, it is intended for specialized scholars and practitioners in the field of smart learning systems.

\subsection{Identification of Literature}

The identification of the relevant research papers for our review follows the research process by Vom Brocke et al. [10], which includes the development of search strings, the consideration of databases, a backward and forward search, and a deep analysis of the identified sources. During the search process, we focused on different smart learning approaches like mobile learning or other smart devices. For this purpose, we used databases that cover interdisciplinary research streams and provide access to peerreviewed journals and renowned conferences [9]. These databases are EBSCO, ProQuest, ScienceDirect, ACM, Taylor \& Francis, Wiley Online Library and AISeL. We researched contributions between 2000 and 2018 within IS and none-IS outlets in order to address knowledge from different disciplines, like educational and psychological research. To identify the relevant literature, we used the following search string \{(e OR mobile OR workplace OR blended OR vocational) AND (learning OR training) AND (context) $\}$. Within the search process, we found 507 papers, whereby 41 were identified as relevant for the study. Moreover, we conducted a backward and forward search to identify other relevant literature for the study. 
As Webster and Watson [9] suggested, we organized the structuring process of the literature in two steps. In the first step, we read the title, abstract and key words of every paper. Within this process, we eliminated papers that have no relation to context factors, learning systems and duplicate findings. In this step, 353 paper were discarded. In the second step, we conducted a full text read. Thereby, we paid particular attention to examining the influence of contextual factors on learning processes and systems. Because the literature regarding context factors in learning systems is not yet well developed, articles from areas such as adult and youth education were also included.

\subsection{Analyzing and Structuring the Literature}

The structuring process of the literature follows the process suggested by Webster and Watson [9] for the categorization of literature. The categorization was conducted in an iterative process. The analyzing and structuring strategy was implemented in a two-step approach. In the first step, the literature was analyzed to find categorization models for context factors in various domains. In the second step, these context factors were analyzed regarding their effect on the learning process and system.

\section{$4 \quad$ Results}

In the first step, we divided the findings of the context factors into four different context types along the recommendations given by Kim and Kim [21], Zhao et al. [22] and Zheng and Yano [11]. After that step, we allocate the context factors found in the literature to the context types. Next, the context factors were selected, which were mentioned at least three times in the literature and had a significant effect on the learning process. This characterization can be seen in Table 4 .

\subsection{Personal Context Factors}

Personal context includes factors that are directly related to the learner itself [27], like their age or gender. In the context of learning systems, five relevant personal context factors are mentioned in the literature.

Internal context describes factors that are related to internal conditions of the learner. In this category, we identified gender, age and previous knowledge as the most influencing factors on the learning process [28-30]. There are lot of different approaches that examine the effect of gender and age on learning success or motivation in e-learning [28, 29, 31]. Regarding the effects of gender on the learning process, Diep et al. [32] examine differences in the perceived learning benefits and the predictive value altruism as a measure of the performance expectancy in terms of their effect on adult learners' online participation. In their results, they found that female learners prefer written communication during the learning process and male learners prefer verbal communication. Hence, we suggest that gender-adapted communication would lead to an improvement in the interaction between actors and thus to an improvement in the co-creation potential. The literature regarding the influence of age on the 
communication and the behavior of learners in TML is still unclear [28, 33]. For example, Ke and Kwak [33] found no difference in the interaction between different age groups in online environments. Previous knowledge is one of the most examined context factors for trainings [34]. There are various approaches investigating the influence of previous knowledge on the learning process [30,35]. This is not surprising, since the adaptation of the learning content on the knowledge level of the learner is an important prerequisite for successful learning.

External context factors mentioned effects of external conditions on the learning process [21]. Thereby, three external context factors could be identified in the literature review: movement [12, 36], availability [37] and location [38]. Movement indicates whether the learning process takes place when the learner is in motion [21, 36]. In the learning process, a person who is in motion can fulfil less complex learning tasks than persons who are not in motion [39]. Availability describes the possibility of a learner to perform a particular action [36]. Depending on the type of smart product, a certain interaction with it is necessary for the learning process. For example, when using a smartphone, sometimes the usage of both hands is necessary to fulfil the learning tasks [21]. The last context factor in the group of external context factors is location. Location describes the position of the learner [36]. With information about the location of a learner, specific learning content can be used during the learning process.

Table 2: Context Factor in Learning Processes (following the assumptions by Kim et al. [21])

\begin{tabular}{|c|c|c|c|c|}
\hline $\begin{array}{c}\text { Main } \\
\text { Category }\end{array}$ & $\begin{array}{c}\text { Sub } \\
\text { Category }\end{array}$ & $\begin{array}{l}\text { Context } \\
\text { Factors }\end{array}$ & Definition of Context Factors & $\begin{array}{c}\text { Example } \\
\text { Source }\end{array}$ \\
\hline \multirow{6}{*}{$\begin{array}{l}\text { Personal } \\
\text { context }\end{array}$} & \multirow{3}{*}{$\begin{array}{l}\text { Internal } \\
\text { context }\end{array}$} & Gender & Describes the gender of the actor. & [29] \\
\hline & & Age & Describes the age of the actor. & [28] \\
\hline & & $\begin{array}{l}\text { Previous } \\
\text { knowledge }\end{array}$ & $\begin{array}{l}\text { Describes the skills and knowledge of an } \\
\text { actor regarding a working process. }\end{array}$ & [29] \\
\hline & \multirow{3}{*}{$\begin{array}{l}\text { External } \\
\text { context }\end{array}$} & Availability & $\begin{array}{l}\text { Describes the possibility of an actor to } \\
\text { interact with the system (i.e., with hands). }\end{array}$ & [36] \\
\hline & & Movement & $\begin{array}{l}\text { Describes if the actor is currently moving } \\
\text { from one position to another }\end{array}$ & [12] \\
\hline & & Location & Describes the position of the actor. & [38] \\
\hline \multirow{5}{*}{$\begin{array}{c}\text { Environ- } \\
\text { mental } \\
\text { context }\end{array}$} & \multirow{2}{*}{$\begin{array}{l}\text { Physical } \\
\text { context }\end{array}$} & $\begin{array}{c}\text { Visual } \\
\text { distraction }\end{array}$ & $\begin{array}{l}\text { Describes factors that distract the actor } \\
\text { through visual stimuli. }\end{array}$ & {$[40]$} \\
\hline & & $\begin{array}{l}\text { Auditory } \\
\text { distraction }\end{array}$ & $\begin{array}{l}\text { Describes factors that distract the actor } \\
\text { through auditory stimuli. }\end{array}$ & [40] \\
\hline & \multirow{3}{*}{$\begin{array}{l}\text { Social } \\
\text { context }\end{array}$} & $\begin{array}{c}\text { Interaction } \\
\text { with } \\
\text { Supervisors }\end{array}$ & $\begin{array}{l}\text { Describes if the actor communicates with } \\
\text { their supervisor(s). }\end{array}$ & {$[41]$} \\
\hline & & $\begin{array}{l}\text { Interaction } \\
\text { with Peers }\end{array}$ & $\begin{array}{c}\text { Describes if the actor communicates with } \\
\text { their peers. }\end{array}$ & [49] \\
\hline & & $\begin{array}{c}\text { Co- } \\
\text { Location }\end{array}$ & $\begin{array}{l}\text { Describes how crowded the actor's } \\
\text { immediate environment is. }\end{array}$ & {$[48]$} \\
\hline
\end{tabular}




\subsection{Environmental Context Factors}

Environmental context includes factors that correlate to the learners' environment [11]. We distinguish between physical context factors, which describe effects related to physical aspects of the environment during the learning process, and, social context factors, which describe effects related to social contacts during the learning process.

In the literature, two factors in particular can be assigned to the subcategory of physical context: Visual and auditory distraction [38, 40]. These factors describe the distraction that the learner experiences through sounds or movements in their environment. For example, the training in production is often organized close to the workplace. In these in-process learning situations, distractions such as noise pollution occur [40] that distract learners and limit the usage of smart devices for learning processes.

In the sub category of social context, there are two important factors that should be mentioned: The interaction with supervisors and the interaction with peers [37]. The supervisor is the central contact person for every employee in the company [42] in the event of problems or questions regarding the work process or social problems between employees. On the other hand, peers are one of the most important information sources for new employees [43] because peers have the same status and (almost) the same level of knowledge. Moreover, the relationship between peers is based on a different standard than the one with the supervisor [22]. At the same time, feedback is available faster from peers than from supervisors [43]. However, peers are not experts, so the recommendations from colleagues are not as professional as those from supervisors [22, 43]. Another important social context factor is co-location [21, 44]. Garcia-Cabot et al. [38] define co-location as the number of other people in the learner's environment. These people can disturb the learner during the process and influence their behavior within the learning process [21].

\subsection{Value Co-Creation in Smart Learning}

To facilitate theory development, as Hong et al. [23] suggests, we develop in the following a conceptual model that provides actionable advice on how context factors in smart learning can be considered. The aim of the model is, on the one hand, to better understand the co-creation process in smart learning systems. On the other hand, we want to explain how context factors can be taken into account to enhance this process.

Smart learning systems can enable value co-creation by taking context factors of all actors into account [15]. Learning processes are characterized by an exchange of knowledge and skills between learners, organizations and learning systems (see figure 1). For example, by taking the learner's previous knowledge into account, it is possible to offer appropriate learning content for the learning process. The coordinated learning content enables the learner to actively participate in the learning process and thereby promotes exchanges between the learner, the learning system and the teacher. This reciprocal learning process is controlled by smart learning products [45]. Therefore, all 
actors acquire knowledge and skills through the context adaptation of the system. In our model, we distinguish central learners from organizational learners. The central learner can be defined as the learning person, for example, a new employee. Organizational learners are persons who act as a teacher for the central learner. This includes peers and supervisors. Both actors interact through the smart learning system. For this purpose, they use smart products, which can measure the condition of context factors through their sensors. Through this interaction, learners can work on learning objectives and teachers can develop their pedagogical skills. By explaining the work process to the learner, the supervisor and peers gain new insights about it because they can analyze the process from a completely different perspective. This increases the value of the learning system both for the learner, who can do work better with learning materials and feedback adapted to context, and for the supervisor, who can train his employees faster and more purposefully.

Value is created within the smart learning co-creation process through the interaction between the learners as well as with the learning system [17, 46]. Therefore, the consideration of context factors must be taking place on the side of the central learner as well as on the side of the organizational learners. In order to take these considerations into account, we implement context factors on both sides of the model. As already mentioned, the actors use smart products to interact with each other. The smart product uses the built-in sensors and the data input by the actor to adapt the learning interface. With these data, the smart learning system can adapt automatically to a variety of context factors, i.e., internal context factors like previous knowledge or external factors like location.

Following these assumptions, we conceptualize our value co-creation framework to explain how context can enhance this process. To conceptualize our smart learning service model, we use the foundation provided by Beverungen et al. [25] to explain how value within the co-creation can be created. For this purpose, we use the smart products as boundary objects that integrate resources and activities from the learner and the organization. The functions of the smart product are a basic condition for the acquisition of context factors. For instance, in industry production processes, many sensors are used to record the condition of a machine in order to draw conclusions about its performance and identify problems at an early stage [47]. To describe the functions of the smart product in detail, we use the framework by Porter and Heppelmann [8] to explain the capabilities of smart products in the learning process. To describe the effects of context factors within this system, we adapted these capabilities for the affordances of the context consideration in the learning process. The value co-creation framework can be seen in Figure 1.

After the explanation of the building blocks of the model, we now illustrate how learning processes in these smart learning systems are enabled and shaped by considering context factors. In order to better understand the learning process, we will explain it using an example from the digitalized production. On the one hand, we use this example, since in digitalized production processes, the need for upskilling on the job is particularly high. On the other hand, the use of smart learning systems is most widespread [48]. 


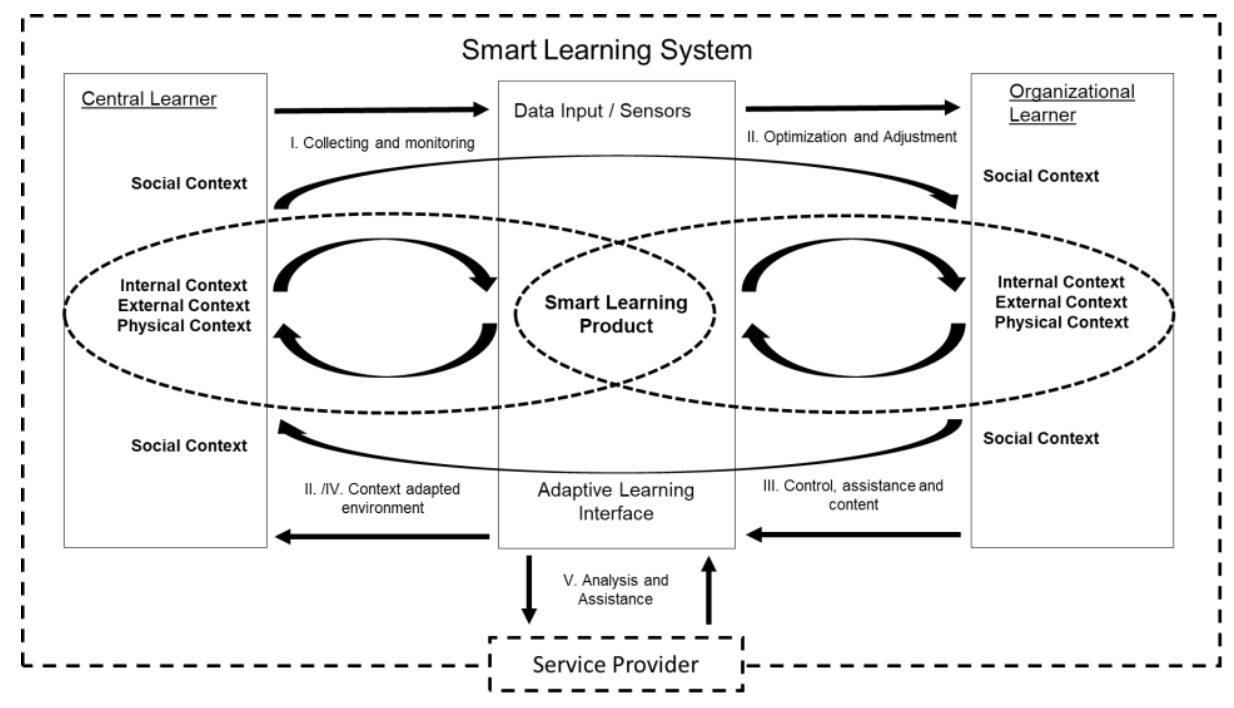

Figure 1: Value Co-Creation Framework with Consideration of Context Factors

I. Collecting and monitoring: The learning process requires metadata of the actors in the system. Due to the data input of the learner, the system receives information about several context factors of the person. For example, the smart learning system gets information about internal context factors (age and gender) (I.). This collection of information about context factors using the data input from users is an easy possibility to adapt the learning system to the context of the learner. Oftentimes, the previous knowledge is also collected through the input of the learner [11], e.g., initial assessments. This collection of the previous knowledge directly by the learners makes sense because the (in-) direct measurement of this context factor via sensors would be very costly or impossible, e.g., collecting information about failures. The information from the sensors and the user is also used to get information about the physical and external context. In the digitalized industry scenario, the auditory distraction can be measured by the sensors [12]. Other information, like the interaction with peers or supervisors, is gained from the data input by the employee itself. For instance, the employee uses a Amazon Alexa to call for support from colleagues when he needs assistance and has not time to call them.

II. Optimization and Adjustment: In our smart learning service model, we distinguish two information flows at the corporate level. First, the collected and monitored information by the smart product can be directly used to adapt the learning environment (II./IV.), especially with the help of artificial intelligence approaches. Second, the information can be used to optimize the content for the learner and for the adjustment of the learning interface (II.). In the following, we will describe the process of optimization and adjustment. Smart learning systems enable supervisors and peers to monitor the learning process of their employees (II). Therefore, learning systems create value for the peers and the supervisor by giving them a detailed overview of the learning process of the employee. This gives the opportunity to optimize the learning process to 
the requirements of the teacher and the learner. Teachers (peers and supervisor) can plan their teaching in more detail and learners are enabled to better organize their learning process [41].

III. Control, assistant and content: In production processes, certain documentation about learning processes is necessary. Thereby, knowledge about certain context factors within learning systems can help to increase the transparency of learning processes and reduce the burden of documentation. Moreover, this transparent organization of the learning process enables the opportunity to optimize the affordances of the learner in the learning process. The adaption simplifies the handling of the learning content and environment (III) and improves the knowledge acquisition of the employees [41]. Hence, it can provide the learner with possible solutions for problems, which in turn prevent the learner from experiencing frustration with seemingly unsolvable tasks [49].

II./IV. Context-adapted environment: Based on the context factors determined, the learning system can adapt the learning interface to these factors. Depending on whether this adjustment takes place automatically (II./IV.) or by data input from the learner (II./IV.), learning interfaces can be adapted. Bentley et al. [50], for example, developed a healthcare application that adapts automatically to the location and time context. Nonetheless, other context adaptions are also possible when simply looking at the learning approach used. Research for instance suggests that some learners might be more advanced learners and, thus, they might need and receive other support measures during their learning process [51].

V. Analysis and Adjustment: The condition of context factors have also an impact to other service providers, also described as value-in-context in complex service ecosystems [52]. Thereby, knowledge about these factors offers the opportunity to create better and more appropriate learning opportunities for the company and the learner itself. Service providers could relate to external providers (for example in the context of industrial services a special-purpose machinery), who could provide analysis guidance in developing the smart learning product (for instance a training for the maintenance of a robot). Internal providers for example could simply include internal IT departments providing infrastructure services in a university of company but also other internal services such as quality management.

\section{Discussion}

Our study shows the need for a deeper consideration of context factors in the learning system. As shown in our model, considering the learning process in TML as a service system has several advantages. First, this view allows us to explain how the consideration of context factors in the learning process can create value for learners and teachers. Second, this allows us to explain the role of smart products in the perception of context factors in learning processes. Third, this view helps to explain how the condition of context factors is recorded in the learning system and how smart products can be used to take these factors into account. Below, we discuss the theoretical and practical contributions our study results provide. 


\subsection{Theoretical Implications}

Our paper makes several contributions to the existing body of literature. When answering our first research aim, we identified context factors in learning processes and frameworks to structure these factors. We contribute to TML research in particular by providing a framework to structure context factors in training situations. By using the foundation provided by Kim and Kim [21], we developed a categorization to structure the identified context factors. Overall, we were able to identify 11 context factors for four categories. By means of this study, we are able to explain which context factors have an influence on learning processes in TML. Thus, we offer a foundation for the development of smart context-sensitive learning systems. Therefore, we enrich the existing body of literature by adding and sharpening dimensions for context factors in TML approaches.

Additionally, we contribute to the body of literature by describing the learning process in TML as a service system. As pointed out by Söllner et al. [6], TML should deliver a high-quality process that is well designed and integrates technologies into the learning process. Through the consideration of the TML learning process as a service system, we were able to explain how and where context factors influence the system. For this, we used the smart product model introduced by Beverungen et al. [25] to explain how context factors in a smart learning system can be measured to capture the current condition of learners and their environment. By means of our model, we help to explain how value is created within smart learning systems. In addition, we highlight that, during the learning process, both learners and teachers receive value through the interaction within the smart learning system. Therefore, we enrich the existing body of literature by explaining how smart learning systems can improve this interaction between learners, peers and supervisors. Moreover, by using our model, we are able to explain when an independent reaction of the smart learning system to context factors is conceivable and how these interactions in the service system create value.

\subsection{Practical Implications}

Due to the multitude of emerging digital learning systems in trainings, our paper aids practitioners to identify relevant factors in the learning process for later consideration within a learning system (see table 2). Moreover, we can help educational service providers to develop smart learning services, which are not only tailored to the needs of the company itself but also to the needs of the individual learner. Thereby, we show how the consideration of context factors can enhance the value of such smart learning systems from educational service providers. In particular, we help practitioners in the industry context to understand how the consideration of context can enhance the learning process in their learning systems. Concerning our results, practitioners deploying smart learning services should heavily concentrate on the structure of the service system to understand how context factors in the system can enhance the value co-creation. 


\section{Limitations, Future Research, and Conclusion}

We acknowledge several limitations to our research, which then underline the need for future research. We investigated a conceptual model for smart learning services. For this purpose, we used the results from a literature review to develop a model to explain how context can be considered within the learning system. Therefore, we suggest operationalizing and evaluating this conceptual model using existing context-sensitive smart learning systems by utilizing the proposed linkages. The theoretical propositions proposed in our model should be operationalized in future research and, on the one hand, used for analyzing different smart learning services in order to test the linkages of the model considerations. On the other hand, the proposed flows in the model can inform the design of smart learning services, especially when trying to specifically incorporate different contextual measures to improve the overall service system.

In conclusion, our paper presents a conceptual model for smart learning service systems that take context factors into account. We therefore enrich the body of literature in the context of TML design that utilize smart products in the center of learning systems. For this purpose, we conducted a literature review with the aim to identify relevant context factors within the learning process of trainings. At the same time, we identified several existing context frameworks. With the usage of this characterization, we adapted the model introduced by Beverungen [25] to explain learning service systems that use smart products to consider context factors within learning processes. Therefore, we can explicate how context factors in such a system should be considered to develop a high-quality learning system.

\section{Acknowledgements}

The research presented in this paper was funded by the German Federal Ministry of Education and Research in the context of the project KoLeArn (www.KoLeArn.de), Grant No. 01BE17008A.

\section{References}

1. Nikou, S.A., Economides, A.A.: Mobile-based assessment: A literature review of publications in major referred journals from 2009 to 2018. Computers \& Education, 101-119 (2018)

2. Beverungen, D., Lüttenberg, H., Wolf, V.: Recombinant Service Systems Engineering. Bus Inf Syst Eng 60, 377-391 (2018)

3. Metzger, D., Niemöller, C., Wingert, B., Schultze, T., Bues, M., Thomas, O.: How Machines are Serviced - Design of a Virtual Realitybased Training System for Technical Customer Services. Leimeister, J.M.; Brenner, W. (Hrsg.):

Proceedings der 13. Internationalen Tagung Wirtschaftsinformatik (WI 2017), St. Gallen, S. 604-618, 604-618 (2017)

4. Bouw, E., Zitter, I., Bruijn, E. de: Characteristics of learning environments at the boundary between school and work - A literature review. Educational Research Review 26, 1-15 (2019)

5. Knote, R., Janson, A., Eigenbrod, L. \& Söllner, M.: The What and How of Smart Personal Assistants: Principles and Application Domains for IS Reserach. Multikonferenz Wirtschaftsinformatik (MKWI). Lüneburg, Germany. (2018) 
6. Söllner, M., Bitzer, P., Janson, A., Leimeister, J.M.: Process is king: Evaluating the performance of technology-mediated learning in vocational software training. J Inf Technol 33, 233-253 (2018)

7. Becker, M., Spöttl, G., Fischer, M. (eds.): Von der Arbeitsanalyse zur Diagnose beruflicher Kompetenzen. Methoden und methodologische Beiträge aus der Berufsbildungsforschung. Peter Lang GmbH Internationaler Verlag der Wissenschaften, Frankfurt a.M (2011)

8. Porter, M.E., Heppelmann, J.E.: How Smart, Connected Products Are Transforming Competition. Harward Business Review, 1-23 (2014)

9. Webster, J., Watson, R.T.: Analyzing the Past to Prepare for the Future: Writing a literature Review. MIS Quarterly (2002)

10. Vom Brocke, J., Simons, A., Niehaves, B., Reimer, K., Plattfaut, R., Cleven, A.: Reconstructing the giant: On the importance of rigour in documenting the literature search process. 17th European Conference on Information Systems (ECIS) 2009. Proceedings (2009)

11. Zheng, Y., Yano, Y.: A framework of context-awareness support for peer recommendation in the e-learning context. Br J Educ Technol 38, 197-210 (2007)

12. Kjeldskov, J., Paay, J.: Indexicality: Understanding Mobile Human-Computer Interaction in Context. ACM Transactions on Computer-Human Interaction 17, $1-28$ (2010)

13. Alavi, M., Leidner, D.E.: Research Commentary: Technology-Mediated Learning - A Call for Greater Depth and Breadth of Research. Information Systems Research 12, 1-10 (2001)

14. Knote, R., Janson, A., Söllner, M. \& Leimeister, J. M.: Classifying Smart Personal Assistants: An Empirical Cluster Analysis. Hawaii International Conference on System Sciences (HICSS). Maui, USA (2019)

15. Hwang, G.-J.: Definition, framework and research issues of smart learning environments - a context-aware ubiquitous learning perspective. Smart Learn. Environ. 1, 492 (2014)

16. Serrano, M.-Á., Vidal-Abarca, E., Ferrer, A.: Teaching self-regulation strategies via an intelligent tutoring system (TuinLECweb): Effects for low-skilled comprehenders. J Comput Assist Learn 61, 364 (2018)

17. Maglio, P.P., Vargo, S.L., Caswell, N., Spohrer, J.: The service system is the basic abstraction of service science. Inf Syst E-Bus Manage 7, 395-406 (2009)

18. Maglio, P.P., Kwan, S.K., Spohrer, J.: Commentary-Toward a Research Agenda for Human-Centered Service System Innovation. Service Science 7, 1-10 (2015)

19. Dey, A.K.: Understanding and Using Context. Personal and Ubiquitous Computing 5, 4-7 (2001)

20. Hamidi, H., Chavoshi, A.: Analysis of the essential factors for the adoption of mobile learning in higher education. A case study of students of the University of Technology. Telematics and Informatics, 1053-1070 (2017)

21. Kim, H., Kim, J., Lee, Y.: An Empirical Study of Use Contexts in the Mobile Internet, Focusing on the Usability of Information Architecture. Information Systems Frontiers, 175-186 (2005) 
22. Zhao, K., Zhang, B., Bai, X.: Estimating Contextual Motivating Factors in Virtual Interorganizational Communities of Practice: Peer Effects and Organizational Influences. Information Systems Research 29, 1-18 (2018)

23. Hong, W., Chan, F.K.Y., Thong, J.Y.L., Chasalow, L.C., Dhillon, G.: A Framework and Guidelines for Context-Specific Theorizing in Information Systems Research. Information Systems Research 25, 111-136 (2014)

24. Patrício, L., Pinho, N.F. de, Teixeira, J.G., Fisk, R.P.: Service Design for Value Networks: Enabling Value Cocreation Interactions in Healthcare. Service Science 10, 76-97 (2018)

25. Beverungen, D., Müller, O., Matzner, M., Mendling, J., Vom Brocke, J.: Conceptualizing smart service systems. Electron Markets 83, 235 (2017)

26. Cooper, H.M.: Organizing knowledge syntheses: A taxonomy of literature reviews. Knowledge in Society 1, 104-126 (1988)

27. Muhamad, M., Idris, K.: Workplace learning in Malaysia: the learner's perspective. International Journal of Training and Development, 62-78 (2005)

28. Brown, S.A., Dennis, A.R., Venkatesh, V.: Predicting Collaboration Technology Use: Integrating Technology Adoption and Collaboration Research. Journal of Management Information Systems 27, 9-54 (2010)

29. Behrend, T.S., Thompson, L.F.: Using animated agents in learner-controlled training: the effects of design control. International Journal of Training and Development 16, 263-283 (2012)

30. Chen, C.-M., Lee, T.-H.: Emotion recognition and communication for reducing second-language speaking anxiety in a web-based one-to-one synchronous learning environment. Br J Educ Technol 42, 417-440 (2011)

31. Lu, H.-P., Chiou, M.-J.: The impact of individual differences on e-learning system satisfaction: A contingency approach. Br J Educ Technol 41, 307-323 (2010)

32. Diep, N.A., Cocquyt, C., Zhu, C., Vanwing, T.: Predicting adult learners' online participation: Effects of altruism, performance expectancy, and social capital. Computers \& Education 101, 84-101 (2016)

33. Ke, F., Kwak, D.: Online learning across ethnicity and age: A study on learning interaction participation, perception, and learning satisfaction. Computers \& Education 61, 43-51 (2013)

34. Hung, I.-C., Yang, X.-J., Fang, W.-C., Hwang, G.-J., Chen, N.-S.: A contextaware video prompt approach to improving students' in-field reflection levels. Computers \& Education 70, 80-91 (2014)

35. Garavan, T.N., Carbery, R.: Understanding participation in e-learning in organizations: a largescale empirical study of employees. International Journal of Training and Development 14 (2010)

36. Lee, Y., Iyengar, S.S., Min, C., Ju, Y., Kang, S., Park, T., Lee, J., Rhee, Y., Song, J.: MobiCon: A Mobile Context-Monitoring Platform. Commun. ACM 55, 54-65 (2012)

37. Sambrook, S.: Factors Influencing the Context and Process of Work-Related Learning: Synthesizing Findings from Two Research Projects. Human Resource Development International 8, 101-119 (2005) 
38. Garcia-Cabot, A., de-Marcos, L., Garcia-Lopez, E.: An empirical study on mlearning adaptation: Learning performance and learning contexts. Computers \& Education 82, 450-459 (2015)

39. Ally, M., Tsinakos, A. (eds.): Increasing Access through Mobile Learning. Commonwealth of Learning and Athabasca University, Vancouver (2014)

40. Huang, Y.-M., Chiu, P.-S.: The effectiveness of the meaningful learning-based evaluation for different achieving students in a ubiquitous learning context. Computers \& Education 87, 243-253 (2015)

41. Pappas, I.O., Giannakos, M.N., Sampson, D.G.: Fuzzy set analysis as a means to understand users of 21st-century learning systems: The case of mobile learning and reflections on learning analytics research. Computers in Human Behavior (2017)

42. Bhattacherjee, A.: Social Science Research: Principles, Methods, and Practices. Textbooks Collection, South Florida (2012)

43. Filius, R.M., Kleijn, R.A.M., Uijl, S.G., Prins, F.J., van Rijen, H.V.M., Grobbee, D.E., Kleijn, R.A.M. de: Strengthening dialogic peer feedback aiming for deep learning in SPOCs. Computers \& Education 125, 86-100 (2018)

44. Lin, J.-W., Tsai, C.-W.: The impact of an online project-based learning environment with group awareness support on students with different selfregulation levels: An extended-period experiment. Computers \& Education 99, 28-38 (2016)

45. Gupta, S., Bostrom, R.: Technology-Mediated Learning: A Comprehensive Theoretical Model. JAIS 10, 686-714 (2009)

46. Kieliszewski, C.A., Maglio, P.P., Cefkin, M.: On modeling value constellations to understand complex service system interactions. European Management Journal 30, 438-450 (2012)

47. Demirkan, H., Bess, C., Spohrer, J., Rayes, A., Allen, D., Moghaddam, Y.: Innovations with Smart Service Systems: Analytics, Big Data, Cognitive Assistance, and the Internet of Everything. CAIS 37 (2015)

48. Richter, A., Heinrich, P., Stocker, A., Schwabe, G.: Digital Work Design. Bus Inf Syst Eng 8, 546 (2018)

49. Frohberg, D., Göth, C., Schwabe, G.: Mobile Learning projects - a critical analysis of the state of the art. Journal of Computer Assisted Learning 25, 307 331 (2009)

50. Bentley, F., Tollmar, K., Stephenson, P., Levy, L., Jones, B., Robertson, S., Price, E., Catrambone, R., Wilson, J.: Health Mashups: Presenting Statistical Patterns between Wellbeing Data and Context in Natural Language to Promote Behavior Change. ACM Trans. Comput.-Hum. Interact. 20, 30:1-30:27 (2013)

51. Shin, S., Song, H.-D.: Finding the optimal scaffoldings for learners' epistemological beliefs during ill-structured problem solving. Interactive Learning Environments 24, 2032-2047 (2016)

52. Chandler, J.D., Vargo, S.L.: Contextualization and value-in-context: How context frames exchange. Marketing Theory 11, 35-49 (2011) 